\title{
Polymorphic Forms of Lamivudine: Characterization, Estimation of Transition Temperature, and Stability Studies by Thermodynamic and Spectroscopic Studies
}

\author{
Renu Chadha, Poonam Arora, and Swati Bhandari \\ University Institute of Pharmaceutical Sciences, Panjab University, Chandigarh 160014, India \\ Correspondence should be addressed to Renu Chadha, renukchadha@rediffmail.com \\ Received 4 September 2012; Accepted 27 September 2012 \\ Academic Editors: M. Appell, G. L. Aranovich, and B. Merinov
}

Copyright (c) 2012 Renu Chadha et al. This is an open access article distributed under the Creative Commons Attribution License, which permits unrestricted use, distribution, and reproduction in any medium, provided the original work is properly cited.

\begin{abstract}
The present study is focused on estimation of transition temperature and stability of various forms of lamivudine. The forms were recrystallized from variety of solvents and preliminarily identification on the basis of SEM revealed existence of three forms (Forms I, II, III). DSC scans of Forms I and III show that these are metastable and undergo heat mediated transformation to Form $\mathrm{I}_{\mathrm{H}}$ and Form $\mathrm{III}_{\mathrm{H}}$, respectively. Form II is phase pure with single sharp melting endotherm at $178.6{ }^{\circ} \mathrm{C}$. The thermal events are visually observed by hot stage microscopy. Enthalpy of solution of the forms is endothermic and magnitude varies in the order Form II $>$ Form $\mathrm{I}_{\mathrm{L}}>$ Form $\mathrm{III}_{\mathrm{L}}$ suggesting Form $\mathrm{III}_{\mathrm{L}}$ to be least crystalline which is well correlated with XRPD data. The transition temperature of the polymorphic pairs $\mathrm{I}_{\mathrm{L}} / \mathrm{I}_{\mathrm{H}}$ and $\mathrm{III}_{\mathrm{L}} / \mathrm{III}_{\mathrm{H}}$ derived from enthalpy of solution and solubility data revealed monotropy whereas enantiotropy exists in $\mathrm{III}_{\mathrm{H}} / \mathrm{II}$. The slurry experiments showed Form II to be thermodynamically most stable. Forms $\mathrm{I}_{\mathrm{L}}$ and $\mathrm{III}_{\mathrm{L}}$ though stable in water are converted to Form II in ethanol, acetonitrile, and propanol after 1 day. Form $\mathrm{III}_{\mathrm{L}}$ is converted to Form $\mathrm{I}_{\mathrm{L}}$ in water after 7 days and the observation is of importance as this instability can effect the pharmaceutical preparations whereas Form $\mathrm{I}_{\mathrm{L}}$ shows a balance between stability and solubility.
\end{abstract}

\section{Introduction}

The increasing recognition of the importance of polymorphism to the pharmaceutical drug industry has generated a great deal of interest and the field has been evolving rapidly [1]. In fact, the systematic evaluation and characterization of the polymorphic forms of the drugs is essential and mandatory because important properties such as solubility and drug stability depend on the solid state structure $[2,3]$. The thermodynamic relationships between polymorphic pairs classified as monotropic or enantiotropic, first developed by Berger and Ramberger, is of utmost importance and must be established carefully and accurately because as drug crystallizes from different solvents the kinetically favoured metastable polymorph appears first which can be isolated and characterized and can be formulated under certain conditions [4-6]. This metastable polymorph may undergo heat induced or solvent induced transformation to produce thermodynamically stable form at its own expense $[6,7]$.
Therefore, a precise knowledge of the stability of crystal forms and their interrelationship is critical for formulation development [8]. Thus, the objective of present work is to fully characterize the different polymorphic forms and to study the complex thermodynamic relationship between the polymorphic pairs of lamivudine.

Lamivudine (Figure 1), (2R, cis-4-amino-1-(2-hydroxymethyl-1, 3-oxathiolan-5-yl)-(1H)-pyrimidine-2-one, is a nucleoside reverse transcriptase inhibitor, used for the treatment of acquired immune deficiency syndrome (AIDS) [9]. Lamivudine in combination with other retroviral agents is indicated for the treatment of HIV-1 infection [10]. The solid state chemistry of this drug is of significant pharmaceutical interest as the drug is reported to exist in three crystalline forms. The two forms (Form I and II) reported in 1996 were again studied by Harris et al. in 1997 [11, 12]. Later in 2007, a new patent showing the existence of another polymorphic form III has appeared [13]. Unfortunately, all these studies lack in one or other aspect. The thermodynamic aspects of 


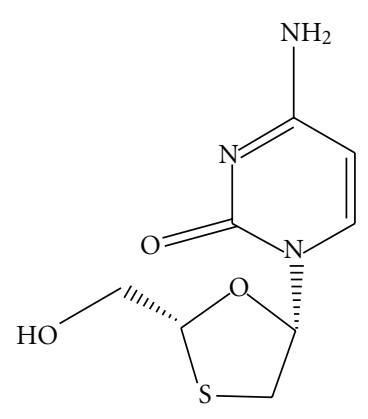

FIgURE 1: Chemical structure of lamivudine.

these polymorphs have not been taken into account and the transformation of one form to another has not been studied extensively. There are many lacunae in the reported literature which need to be filled for complete characterization of these polymorphs. Therefore, the purpose of the present work is to revisit these crystalline forms and the prime objective is to determine transition temperature of a polymorphic pairs and to interpret whether they are monotropically or enantiotropically related. The thermodynamic stability relationship of the polymorphic pair has also been determined from their melting temperature and enthalpy of solution data [14]. Besides this, the heat mediated and solvent mediated transformations are also emphasized in the present work.

\section{Materials and Methods}

2.1. Materials. Lamivudine was obtained as a gift sample from Ranbaxy Laboratories Pvt. Ltd. (Poanta Sahib, India). Analytical grade solvents methanol, ethanol, ethyl acetate, chloroform, acetonitrile, hexane, heptane, 1-butanol, dimethylformamide (DMF), 1, 4-dioxane, and 2-propanol were used in this work.

2.2. Preparation of Polymorphs. The commercial sample of lamivudine was recrystallized from a variety of solvents and their mixtures to generate different crystal forms. Saturated solutions of lamivudine were prepared by heating in different solvents under constant stirring until most of lamivudine dissolved; the solutions were filtered and kept at room temperature until crystallization was complete (slow recrystallization). The further analysis of the recrystallized product by DSC and XRPD techniques showed that the crystallization ultimately resulted in only three polymorphic forms. Table 1 summarizes the different solvent systems leading to the formation of the three distinct crystal forms of lamivudine.

2.3. Thermal Methods of Analysis. The DSC thermograms were obtained on DSC Q20, TA Instruments-Waters LLC, USA. The calorimeter was calibrated for temperature and heat flow accuracy using the melting of pure indium $(\mathrm{mp}$ $156.6^{\circ} \mathrm{C}$ and $\Delta \mathrm{H}$ of $\left.25.45 \mathrm{~J} \mathrm{~g}^{-1}\right)$. A mass between 2 and $8 \mathrm{mg}$ was taken into the aluminium pan, covered with lid and sealed. DSC curves were obtained under a nitrogen purge of
TABLE 1: Different solvent systems to prepare different crystal forms of lamivudine.

\begin{tabular}{lcc}
\hline Solvent system & $\begin{array}{c}\text { Form } \\
\text { obtained }\end{array}$ & Shape \\
\hline $\begin{array}{l}\text { Water, Methanol, } \\
\begin{array}{l}\text { Toluene + ethanol, Ethanol, } \\
\text { DMF + methanol, 1,4-dioxane }\end{array}\end{array}$ & Form I & elongated needles \\
$\begin{array}{l}\text { Ethyl acetate, Dry ethanol, } \\
\text { Acetonitrile, 2-propanol, } \\
\begin{array}{l}\text { Toluene, Dry methanol, } \\
\text { 1,4-dioxane + methanol + water }\end{array}\end{array}$ & Form II & prismatic crystals \\
$\begin{array}{l}\text { Heptane + 1-butanol } \\
\begin{array}{l}\text { Hexane + n-propanol } \\
\text { Chloroform }\end{array}\end{array}$ & Form III & fine needles \\
\hline
\end{tabular}

$50 \mathrm{~mL}$ per minute at a heating rate of $10^{\circ}$ per minute with the temperature range from 50 to $250^{\circ} \mathrm{C}$.

The TGA scans were obtained on TGA, TA InstrumentsWaters LLC, USA. TGA traces were recorded at heating rates of $10^{\circ}$ per minute under a nitrogen purge of $50 \mathrm{~mL}$ per minute. Samples with masses between 1 and $10 \mathrm{mg}$ were analyzed using platinum pan. Mass loss (\%) was calculated based on the mass of the original sample.

2.4. X-Ray Powder Diffraction Analysis. The powder diffraction patterns were recorded on an X-ray diffractometer (XPERT-PRO, PANalytical, Netherlands) with $\mathrm{Cu}$ as tube anode. The diffractograms were recorded under following conditions: voltage $40 \mathrm{kV}, 35 \mathrm{~mA}$, angular range 5 , and fixed divergence slit. Approximately $200 \mathrm{mg}$ of samples were loaded into the sample holder for analysis.

2.5. Scanning Electron Microscopy. A Jeol JSM-6100 scanning electron microscope was used to obtain photomicrographs of lamivudine and its polymorphs. Samples were mounted on a metal stub with an adhesive tape and coated under vacuum with gold.

2.6. Microcalorimetric Study. Calorimetric studies were performed on Microreaction calorimeter obtained from Thermal Hazards Technology, UK. Phosphate buffer ( $\mathrm{pH}$ 7.0) was used to determine the enthalpy of solution and the measurements were performed at $25^{\circ} \mathrm{C}$ and $37^{\circ} \mathrm{C}$. The size of sample used in this study ranged from 1 to $10 \mathrm{mg}$ and was weighed (Sartorius Model CP225D) into a cylindrical glass tube covered with parafilm on one side. This cylindrical tube was submerged into the ampoule containing the solvent. A plunger with a cap was put from the open end of the tube. The same solvent was put into the reference ampoule. These were put into the sample and reference holes until both rest on the base of the holes. The parafilm was shattered mechanically by means of plunger.

2.7. Aqueous Solubility Measurement. MSW-275 (Macro scientific works, New Delhi) shaker was used for measuring aqueous solubility of different forms of lamivudine. Solubility studies were performed by adding $10 \mathrm{mg}$ of sample in 


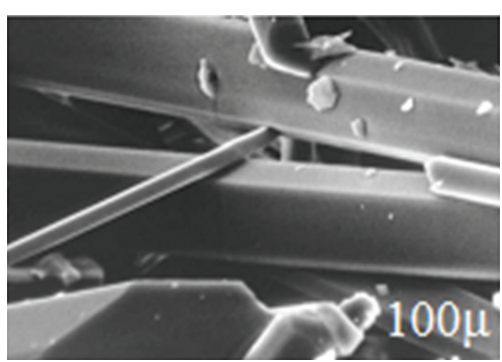

(a)

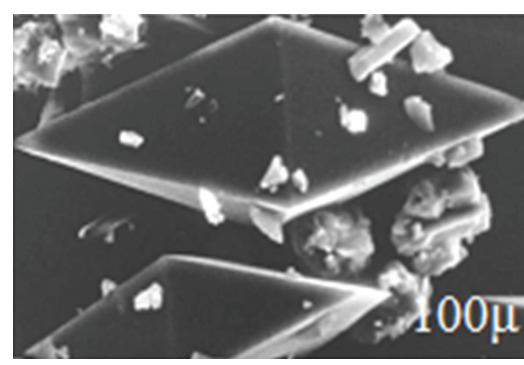

(b)

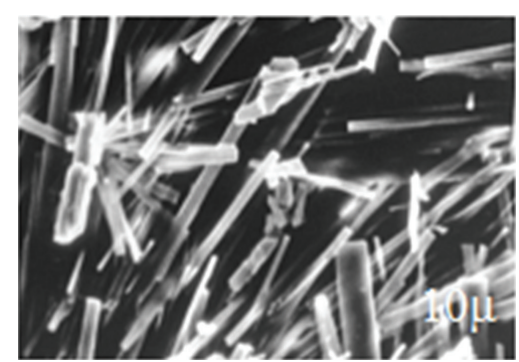

(c)

FIGURE 2: Scanning electron microscopy of (a) Form I, (b) Form II, and (c) Form III of lamivudine.

flask containing $10 \mathrm{~mL}$ of phosphate buffer $\mathrm{pH} 7.0(50 \mathrm{mM})$. The mixture was shaken at $37^{\circ} \mathrm{C}$ for $24 \mathrm{~h}$. The aliquots were filtered through $0.45 \mu \mathrm{m}$ membrane filter and analyzed spectrophotometrically at $270 \mathrm{~nm}$. The standard plot of lamivudine was prepared by dissolving a weighed amount of sample in phosphate buffer $\mathrm{pH} 7.0$, suitably diluted and absorbance taken at wavelength $270 \mathrm{~nm}$ on a spectrophotometer. $E^{1 \%} \mathrm{~cm}$ was calculated.

2.8. Solvent Mediated Transformation Studies. The stability relationships and transformation between polymorphs were assessed at $25^{\circ} \mathrm{C}$ by slurry conversion method. Forms $\mathrm{I}_{\mathrm{L}}$ and $\mathrm{III}_{\mathrm{L}}$ and mixtures of these two forms prepared by mild blending of the solids in 1:1 ratio were suspended in water, ethanol, acetonitrile, and propanol and were maintained under constant shaking. To assess the conversion kinetics, the samples were withdrawn at $24 \mathrm{~h}$ and after 7 days. The suspensions were then filtered and analyzed by DSC and XRPD and compared with the starting material.

\section{Results and Discussion}

3.1. Recrystallization Product. The preliminary investigation of recrystallized product of lamivudine from various solvents by visual inspection and particle morphology by SEM categorized these into three distinct forms. The forms obtained from water, methanol, ethanol, 1,4-dioxane, ethyl acetate, mixture of toluene and ethanol, and a mixture of DMF and methanol showed elongated needle shaped acicular crystals and are designated as Form I (Figure 2(a)). The forms obtained from dry ethanol, dry methanol, 2-propanol, toluene, and a mixture of 1,4-dioxane, methanol, and water showed prismatic crystals indicating these to be similar and are designated as Form II (Figure 2(b)). Form III was obtained from chloroform, a mixture of heptane and 1butanol, and a mixture of hexane and propanol. The crystals of Form III were found to be very fine needles which were easily distinguishable from Form I (Figure 2(c)). Thus on the basis of morphology existence of only three new polymorphic forms was confirmed after screening from various solvents.

3.2. Thermal Analysis of Polymorphic Forms. Investigation of the thermal behavior by DSC and TGA techniques shows the

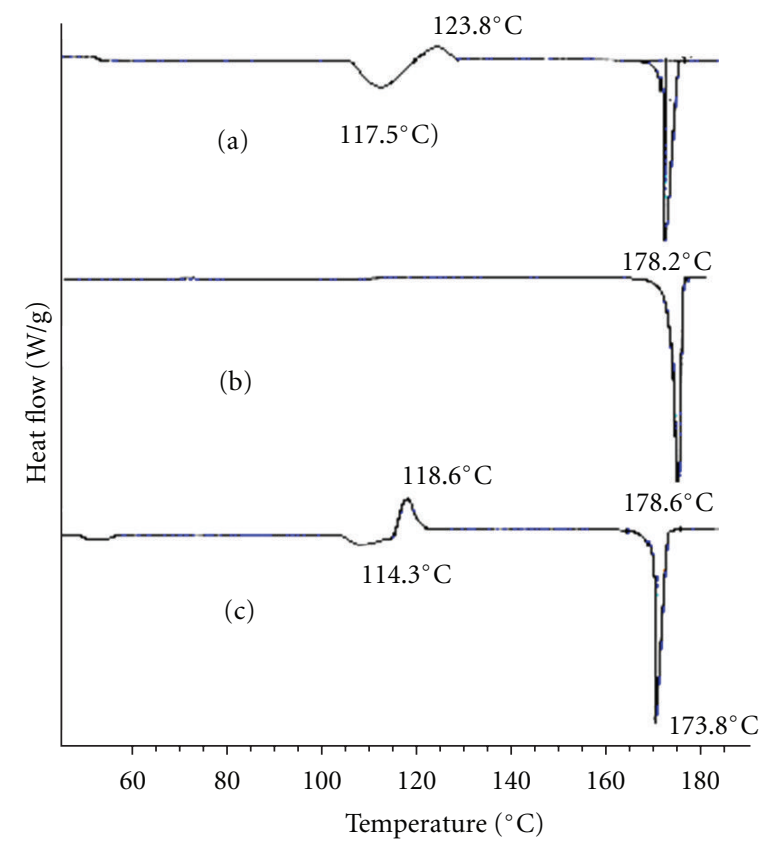

FIGURE 3: DSC plots of (a) Form $\mathrm{I}_{\mathrm{L}}$, (b) Form II, and (c) Form $\mathrm{III}_{\mathrm{L}}$ of lamivudine.

existence of low melting metastable forms before they are converted into higher melting stable forms in Form I and III. Thermodynamic relationship between different phases (enantiotropic or monotropic) and transitions between different crystal forms are determined by employing these techniques. The hot stage microscope provides the visual confirmation of events occurring during the transformation of one form to another.

DSC scan of Form I showed two endotherms peaking at $117.5^{\circ} \mathrm{C}$ and $178.2^{\circ} \mathrm{C}$ separated by an exotherm at $123.8^{\circ} \mathrm{C}$ (Figure 3). Prior to these events there is a very small endotherm in the temperature range $70-100^{\circ} \mathrm{C}$. The thermogravimetric scan confirms the presence of unbound water at a level of $1 \%$ by weight (corresponding approximately to 1 mole of water for every 10 moles of lamivudine) in the temperature range $70-100^{\circ} \mathrm{C}$ (Figure 4 ).

A broad endotherm at $117.4^{\circ} \mathrm{C}$ is not accompanied by any mass loss in TGA scan, suggesting this endotherm to be a melting event and negate the presence of any solvents. 


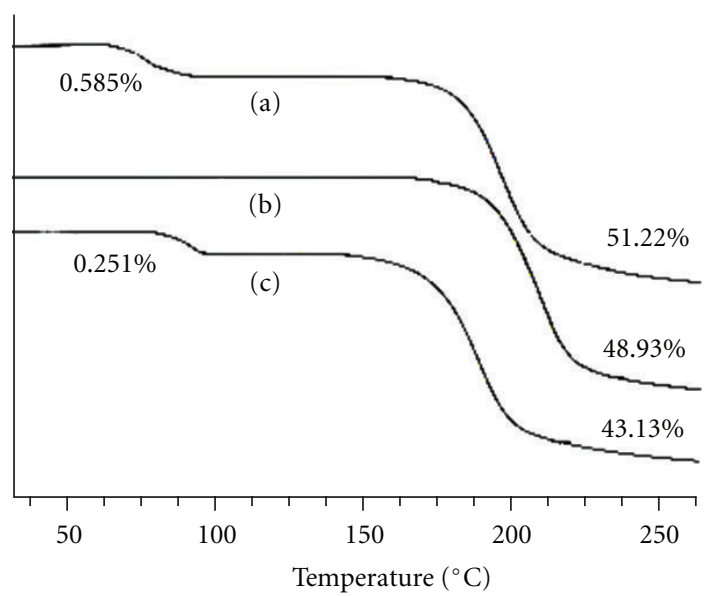

FIgure 4: TGA plots of (a) Form $\mathrm{I}_{\mathrm{L}}$, (b) Form II, and (c) Form $\mathrm{III}_{\mathrm{L}}$ of lamivudine.

This melting is immediately followed by a small exotherm representing either a solid-solid transition or a liquid-solid transition. The exact nature of transition is confirmed by hot stage microscopy which shows that the crystals of Form I start melting at $118^{\circ} \mathrm{C}$; however, the new crystal form starts to grow at $124^{\circ} \mathrm{C}$ from the melt of previous crystals. These crystals finally melt at $178^{\circ} \mathrm{C}$ to give a sharp melting endotherm in the HSM images (Figure 5). These thermal events represent a liquid-solid transition to generate Form $\mathrm{I}_{\mathrm{H}}$ (high melting form) from the melt of Form $\mathrm{I}_{\mathrm{L}}$ (low melting form). This phenomenon suggests this conversion to be heat mediated transformation. The very low enthalpy of fusion indicates that the low melting endotherm is immediately or simultaneously accompanied by exothermic crystallization into other polymorphic form. The Form I prepared in the present study is comparable to some extent with Form I reported in literature $[11,12]$. In both studies the forms showed endo-/exo-events followed by sharp melting endotherm. However, the solvent system used in our study varies from polar to nonpolar whereas the previous authors have used only polar solvents. Moreover, Harris et al. have shown the presence of bound water at a level of $2 \%$ by weight but in our study only unbound nonstoichiometric water is found to be associated. The thermodynamic relationship and the solvent mediated transformations of the forms have not been reported by previous workers and are a part of our work. All these parameters are dealt with in the present work.

Form II showed single sharp melting endotherm at $178.6^{\circ} \mathrm{C}$ in DSC with no mass loss in the TGA scan up to $180^{\circ} \mathrm{C}$ (Figure 4) indicating it to be a phase pure form which is neither solvate nor hydrate. The HSM images show melting around $179^{\circ} \mathrm{C}$ (Figure 6). The melting temperature of Form II suggests this form to be thermodynamically more stable form. The literature survey reveals that a similar form with almost similar melting temperature exists; however, the crystallization solvents are different [12]. Moreover, other parameters such as enthalpy of fusion and visual inspection of melting by HSM are not reported.

Regarding Form III, the preliminary investigation by DSC shows endo-/exopeaks as were observed in Form I. A
TABle 2: Thermal characteristics of Form I, Form II, Form $\mathrm{II}_{\mathrm{H}}$, Form $\mathrm{III}_{\mathrm{L}}$, and Form $\mathrm{III}_{\mathrm{H}}$ of lamivudine by differential scanning calorimetry.

\begin{tabular}{lcc}
\hline Sample & $\begin{array}{c}\text { Melting temperature } \\
\left({ }^{\circ} \mathrm{C}\right)\end{array}$ & $\begin{array}{c}\text { Enthalpy of fusion } \\
(\mathrm{J} / \mathrm{g})\end{array}$ \\
\hline Form $\mathrm{I}_{\mathrm{L}}$ & 117.5 & 19.6 \\
Form $\mathrm{I}_{\mathrm{H}}$ & 178.2 & 109.9 \\
Form II & 178.6 & 90.9 \\
Form $\mathrm{III}_{\mathrm{L}}$ & 114.3 & 13.9 \\
Form $\mathrm{III}_{\mathrm{H}}$ & 173.8 & 43.7 \\
\hline
\end{tabular}

broad endotherm accompanied by mass loss $(0.2 \%)$ in TGA in the temperature range $50-100^{\circ} \mathrm{C}$ suggests unbound solvent in nonstoichiometric ratio whereas the two endotherms peaking at $114.3^{\circ} \mathrm{C}$ and $173.8^{\circ} \mathrm{C}$ separated by an exothermic peak at $118.6^{\circ} \mathrm{C}$ are suggestive of phase-phase transition. The HSM images confirmed it to be a liquid-solid transition to generate Form $\mathrm{III}_{\mathrm{H}}$ (high melting form) from the melt of Form $\mathrm{III}_{\mathrm{L}}$ (low melting form) (Figure 7). This form (Form $\mathrm{III}_{\mathrm{H}}$ ) finally melts at $175.8^{\circ} \mathrm{C}$.

The melting temperature and heat of fusion of the higher melting Form $\mathrm{I}_{\mathrm{H}}$ is similar to the heat of fusion of Form II suggesting that Form $\mathrm{I}_{\mathrm{L}}$ might have converted to Form II after melting; however, the melting temperature and heat of fusion of the higher melting Form $\mathrm{III}_{\mathrm{H}}$ is different which suggests that Form $\mathrm{III}_{\mathrm{L}}$ has converted to a new polymorphic form after melting (Table 2).

3.2.1. Heat Mediated Transformation and Thermodynamic Relationship. Table 2 shows that Forms $\mathrm{I}_{\mathrm{H}}$ or II and $\mathrm{III}_{\mathrm{H}}$ obtained after phase-phase transition (liquid-solid) of Forms $\mathrm{I}_{\mathrm{L}}$ and $\mathrm{III}_{\mathrm{L}}$, respectively, show higher melting temperature and higher enthalpy of fusion suggesting existence of monotropic relationship between them. The polymorphic pair $\mathrm{III}_{\mathrm{H}} / \mathrm{II}$ show enantiotropic transition as the high melting form has lower heat of fusion and the low melting form has higher heat of fusion. The liquid-solid transition as shown by HSM also confirms that the polymorphic pairs $\mathrm{I}_{\mathrm{L}} / \mathrm{II}$ and $\mathrm{III}_{\mathrm{L}} / \mathrm{III}_{\mathrm{H}}$ are monotropically related. To confirm the occurrence of heat mediated transformation of metastable Form $\mathrm{I}_{\mathrm{L}}$ and $\mathrm{III}_{\mathrm{L}}$ to stable forms as well as to determine whether the transition is reversible or irreversible a separate experiment was performed. Forms I and III were heated on a DSC furnace just above the end of crystallization exotherm, cooled to room temperature $\left(28^{\circ} \mathrm{C}\right)$, and heated again to the melting point. It was observed that the first endotherm at $117.4^{\circ} \mathrm{C}$ in Form I and at $116.3^{\circ} \mathrm{C}$ in Form III disappeared in the DSC graph of the repeated heating curve (Figure 8). The first endotherm corresponding to metastable form does not appear in the DSC scan even after 5 days. These heatingcooling experiments suggest kinetically irreversible transition confirming Forms $\mathrm{I}_{\mathrm{L}} / \mathrm{I}_{\mathrm{H}}$ and $\mathrm{III}_{\mathrm{L}} / \mathrm{III}_{\mathrm{H}}$ to be monotropes.

3.3. X-Ray Powder Diffraction (XRPD). One of the reliable ways to distinguish the various forms of lamivudine is with 


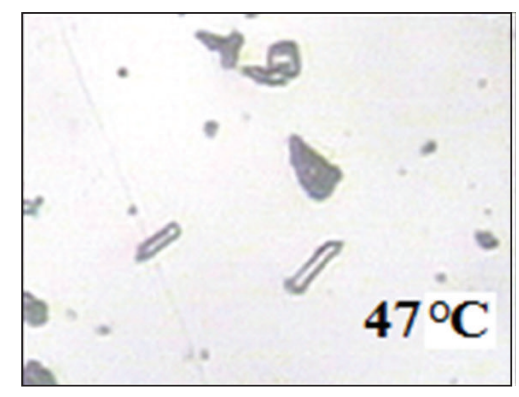

(a)

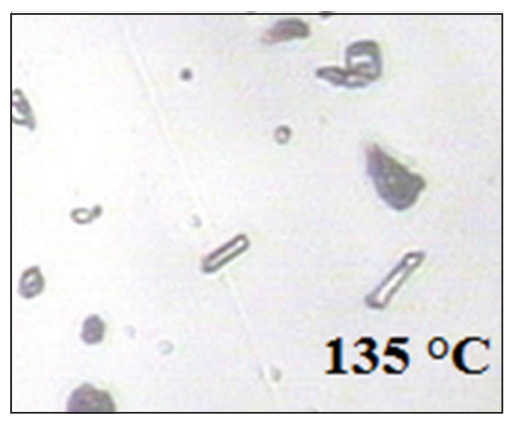

(d)

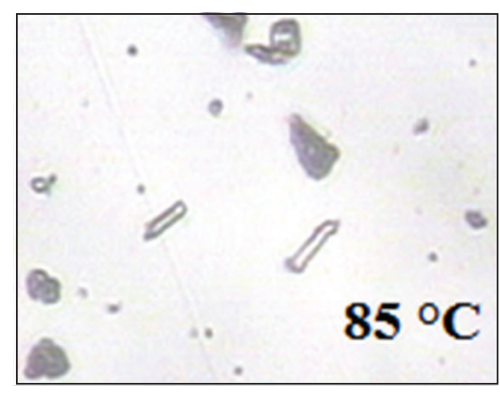

(b)

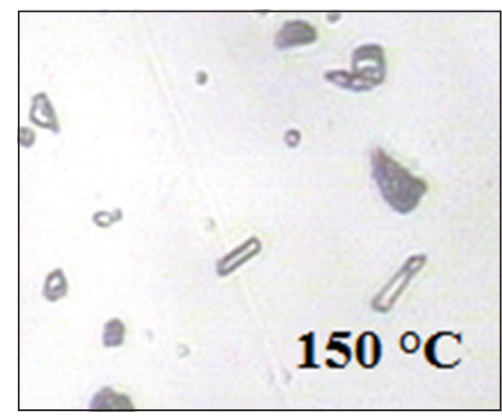

(e)

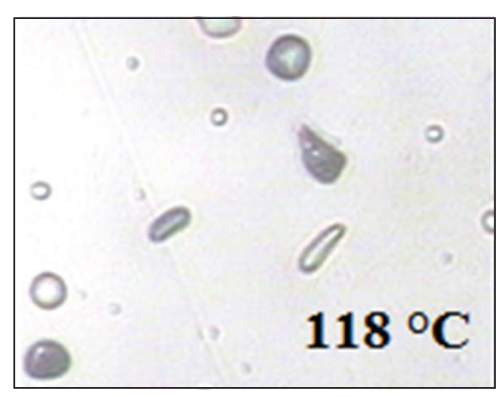

(c)

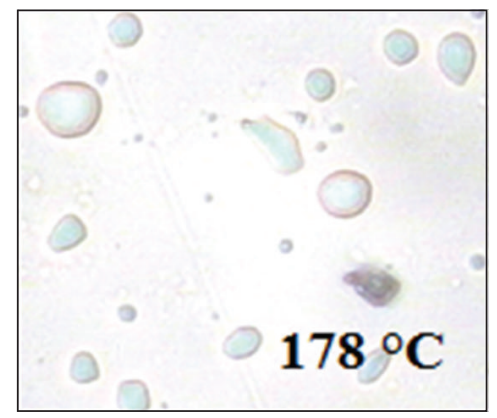

(f)

FIGURE 5: Hot stage micrographs of Form I.

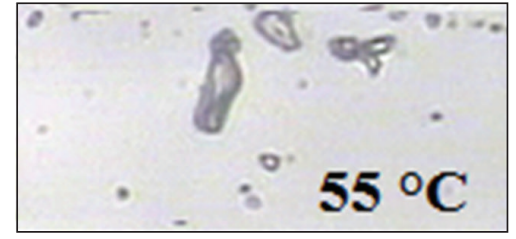

(a)

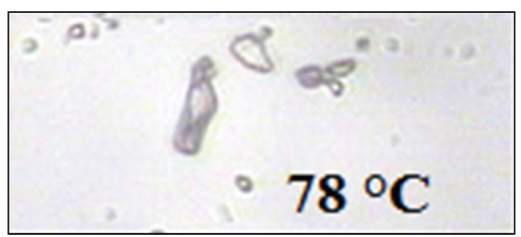

(b)

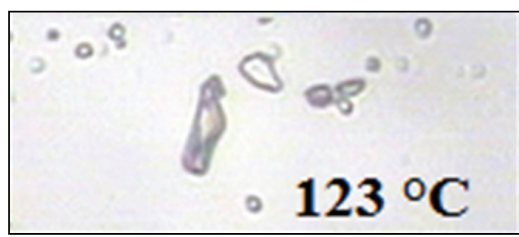

(c)

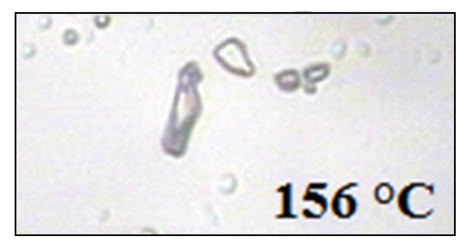

(d)

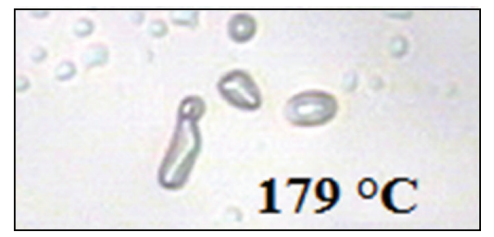

(e)

FIGURE 6: Hot stage micrographs of Form II.

X-ray powder diffraction. The XRPD patterns of Forms $\mathrm{I}_{\mathrm{L}}$, II, and $\mathrm{III}_{\mathrm{L}}$ were recorded at room temperature (Figure 9). All the forms can be easily discriminated by their diffraction pattern particularly by presence and absence of peaks between $9^{\circ}$ and $30^{\circ}$. The XRPD pattern of Form $\mathrm{I}_{\mathrm{L}}$ showed characteristic peaks at $9.0^{\circ}, 10.1^{\circ}, 11.6^{\circ}, 12.1^{\circ}, 13.3^{\circ}, 14.7^{\circ}$, $16.9^{\circ}, 17.5^{\circ}, 18.5^{\circ}, 19.9^{\circ}, 20.5^{\circ}(100 \%$ relative intensity $)$, $24.9^{\circ}, 25.3^{\circ}, 26.4^{\circ}, 27.2^{\circ}$, and $28.3^{\circ}$. The indicative peaks for Form II occur at $11.2^{\circ}, 12.9^{\circ}, 14.5^{\circ}, 15.3^{\circ}, 17.5^{\circ}$, and $18.3^{\circ}$ whereas the characteristic peaks at $22.5^{\circ}, 31.0^{\circ}, 33.9^{\circ}$, and $35.4^{\circ}$ were absent as compared to Form $\mathrm{I}_{\mathrm{L}}$ indicating formation of a new phase. The XRPD pattern of Form III $_{\mathrm{L}}$ showed new peaks at $9.9^{\circ}, 10.8^{\circ}, 11.8^{\circ}, 12.8^{\circ}, 13.1^{\circ}, 18.4^{\circ}$, $19.0^{\circ}, 31.0^{\circ}, 36.2^{\circ}$, and $36.7^{\circ}$ making it different from the other two forms. This form also showed the absence of peak at $14.3^{\circ}$.

3.3.1. Conformation of Heat Mediated Transformation with $X R P D$. In order to explicitly identify to which form the lower melting forms have transitioned to upon heating, different heating experiments were performed. Forms $\mathrm{I}_{\mathrm{L}}$ and $\mathrm{III}_{\mathrm{L}}$ were heated at temperature $135^{\circ} \mathrm{C}$ and $130^{\circ} \mathrm{C}$, respectively, and held at this temperature for 50 min to ensure complete conversion. The samples were then cooled to room temperature in a desiccator with zero relative humidity and were subjected to XRPD to identify the resulting forms. The XRPD pattern of Form $\mathrm{I}_{\mathrm{H}}$ corresponds well to the pattern reported for Form II which revealed that this form transferred to Form II 


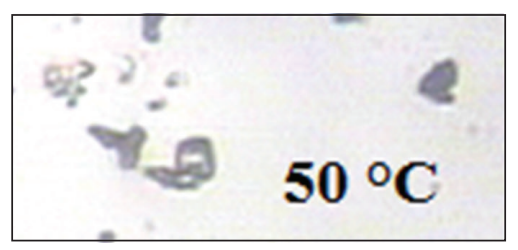

(a)

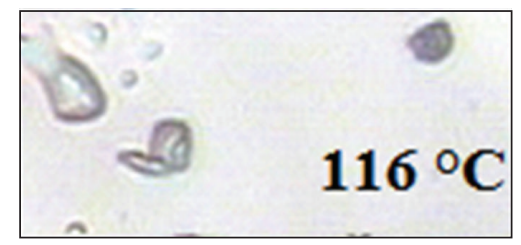

(d)

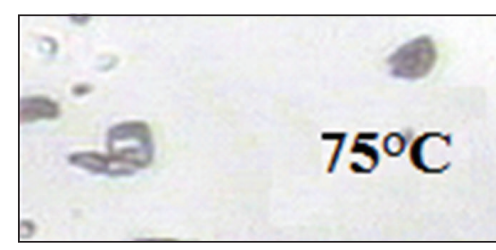

(b)

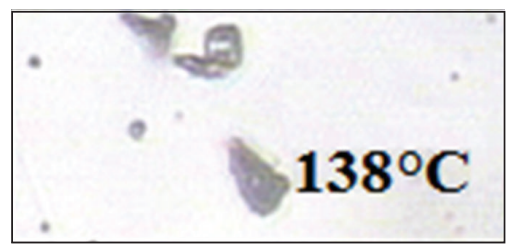

(e)

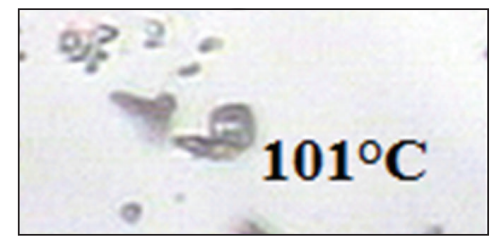

(c)

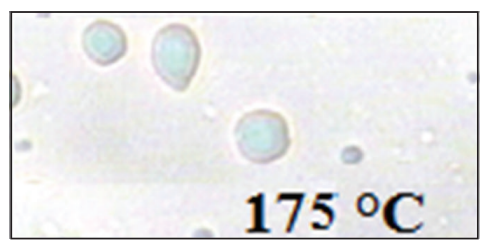

(f)

FIGURE 7: Hot stage micrographs of Form III.

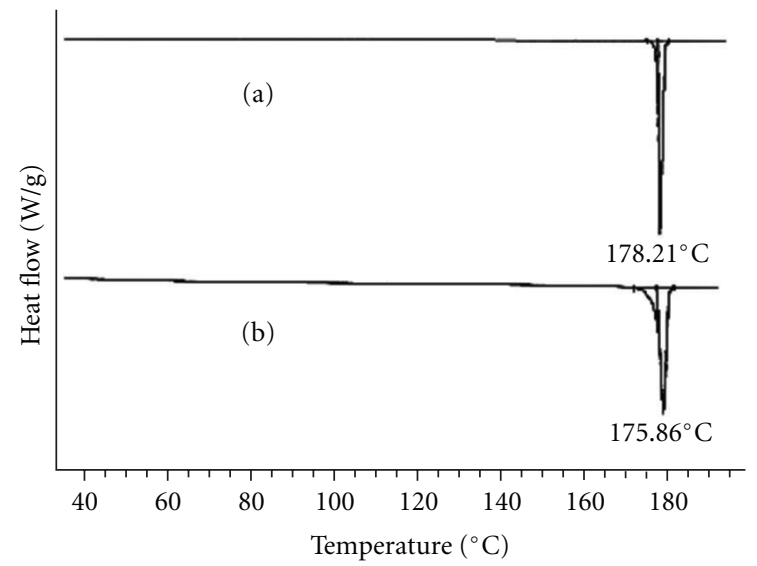

Figure 8: DSC plots of (a) Form $\mathrm{I}_{\mathrm{H}}$ and (b) Form $\mathrm{III}_{\mathrm{H}}$ of lamivudine.

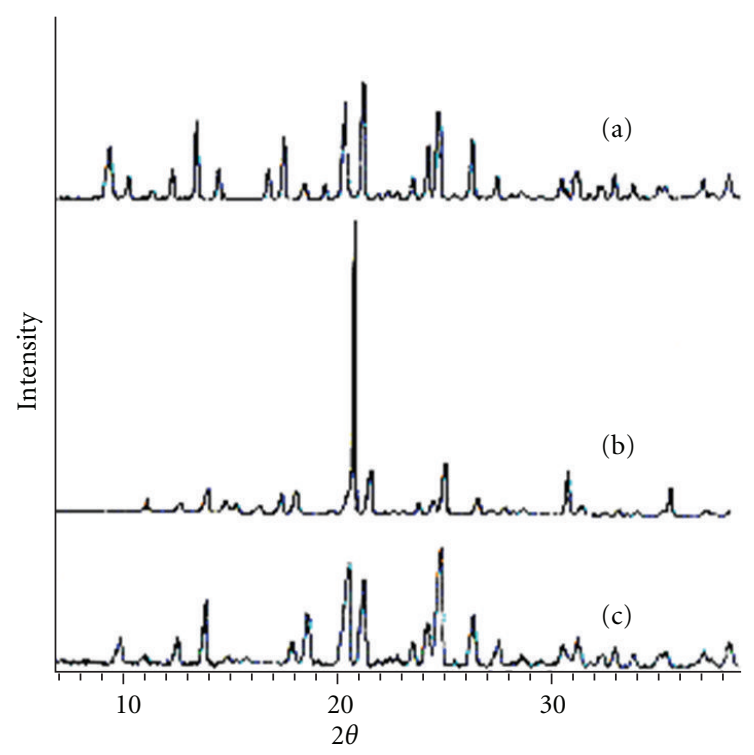

Figure 9: XRPD patterns of (a) Form $\mathrm{I}_{\mathrm{L}}$, and (b) Form II, and (c) Form III $_{\mathrm{L}}$ of lamivudine.
TABLE 3: Enthalpy of solution and solubility of Form I, Form $\mathrm{II}_{\mathrm{L}}$, Form $\mathrm{II}_{\mathrm{H}}$, Form $\mathrm{III}_{\mathrm{L}}$, and Form $\mathrm{III}_{\mathrm{H}}$ of lamivudine.

\begin{tabular}{lcccc}
\hline Sample & \multicolumn{2}{c}{$\begin{array}{c}\text { Enthalpy of solution } \\
(\mathrm{kJ} / \mathrm{mol})\end{array}$} & \multicolumn{2}{c}{$\begin{array}{c}\text { Solubility } \\
\left(\times 10^{-1} \text { moles } / \mathrm{L}\right)\end{array}$} \\
& $25^{\circ} \mathrm{C}$ & $37^{\circ} \mathrm{C}$ & $25^{\circ} \mathrm{C}$ & $37^{\circ} \mathrm{C}$ \\
\hline Form $\mathrm{I}_{\mathrm{L}}$ & 17.72 & 18.73 & 0.42 & 0.46 \\
Form $\mathrm{I}_{\mathrm{H}}$ & 18.22 & 19.45 & 0.39 & 0.41 \\
Form II & 18.83 & 19.90 & 0.38 & 0.40 \\
Form $\mathrm{III}_{\mathrm{L}}$ & 12.87 & 14.99 & 0.58 & 0.61 \\
Form $\mathrm{III}_{\mathrm{H}}$ & 14.13 & 16.12 & 0.48 & 0.52 \\
\hline
\end{tabular}

upon heating. However, The XRPD pattern of Form $\mathrm{III}_{\mathrm{H}}$ showed appearance of new peaks at $8.3^{\circ}, 12.8^{\circ}, 19.0^{\circ}$, and $29.6^{\circ}$ indicating formation of a new phase (Figure 10). This supports the observation made by DSC that Form $\mathrm{I}_{\mathrm{L}}$ has converted to Form II and Form III $_{\mathrm{L}}$ has converted to a new polymorphic form after heat mediated transformation.

3.4. Solution Calorimetry. The enthalpy of solution has been utilized to differentiate the metastable Forms $\mathrm{I}_{\mathrm{L}}$ and $\mathrm{III}_{\mathrm{L}}$ from the stable high melting forms $\mathrm{I}_{\mathrm{H}}$ and $\mathrm{III}_{\mathrm{H}}$. Moreover, this data is also required to determine the transition temperature for conversion of metastable forms to stable forms and to determine the stability relationship in a particular polymorphic pair. The molar enthalpy of solution $\left(\Delta_{\text {sol }} \mathrm{H}\right)$ determined in phosphate buffer $\mathrm{pH} 7.0$ at $25^{\circ} \mathrm{C}$ and $37^{\circ} \mathrm{C}$ is given in Table 3. All the forms showed endothermic behavior and the absolute value of molar enthalpy of solution followed the order: Form II $>$ Form $\mathrm{I}_{\mathrm{L}}>$ Form $\mathrm{III}_{\mathrm{L}}$. The highest endothermic $\Delta_{\text {sol }} \mathrm{H}$ associated with Form II and this is very well correlated with XRPD studies. Form $\mathrm{I}_{\mathrm{L}}$ is less endothermic, less crystalline, and obviously less stable. These results are somewhat contrary to the results reported by Jozwiakowski et al. The authors have determined the $\Delta_{\text {sol }} \mathrm{H}$ of Forms I and II in various solvents ranging from water to alcohols and have shown Form II to be less endothermic 
TABLE 4: The enthalpy of transition $(\Delta \mathrm{H}(\mathrm{T}))$, free energy of transition $(\Delta \mathrm{G}(\mathrm{T}))$, entropy of transition $(\Delta \mathrm{S}(\mathrm{T}))$, and transition temperature $\left(T_{t}\right)$ of different polymorphic pairs at $25^{\circ} \mathrm{C}$ and $37^{\circ} \mathrm{C}$.

\begin{tabular}{lcccccrrr}
\hline & \multicolumn{2}{c}{$\Delta \mathrm{H}_{\text {trans }}(\mathrm{kJ} / \mathrm{mol})$} & \multicolumn{2}{c}{$\Delta \mathrm{G}_{\text {trans }}(\mathrm{kJ} / \mathrm{mol})$} & \multicolumn{2}{c}{$\Delta \mathrm{S}_{\text {trans }}(\mathrm{J} / \mathrm{mol})$} & \multicolumn{2}{c}{$T_{t}(\mathrm{~K})$} \\
& $25^{\circ} \mathrm{C}$ & $37^{\circ} \mathrm{C}$ & $25^{\circ} \mathrm{C}$ & $37^{\circ} \mathrm{C}$ & $25^{\circ} \mathrm{C}$ & $37^{\circ} \mathrm{C}$ & $25^{\circ} \mathrm{C}$ & $37^{\circ} \mathrm{C}$ \\
\hline Form $\mathrm{I}_{\mathrm{L}} \rightarrow \mathrm{II}$ & -0.49 & -0.72 & -0.18 & -0.26 & -1.05 & -1.52 & 467.6 \\
Form $\mathrm{III}_{\mathrm{L}} \rightarrow \mathrm{III}_{\mathrm{H}}$ & -1.26 & -1.13 & -0.45 & -0.41 & -2.72 & -2.42 & 468.5 \\
Form $\mathrm{III}_{\mathrm{H}} \rightarrow \mathrm{II}$ & -4.69 & -3.87 & -0.57 & -0.64 & -13.84 & -10.83 & 339.4 & 340.4 \\
\hline
\end{tabular}

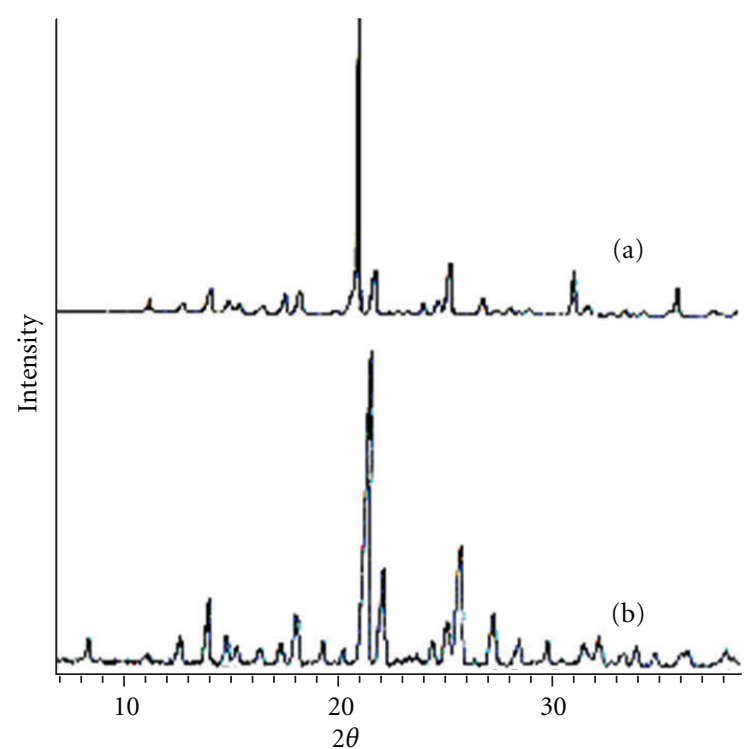

FIGURE 10: XRPD patterns of (a) Form $\mathrm{I}_{\mathrm{H}}$ and (b) Form $\mathrm{III}_{\mathrm{H}}$ of lamivudine.

than Form $\mathrm{I}_{\mathrm{L}}$ whereas in the present study Form II is more endothermic. This variation may be due to the fact that Form $\mathrm{I}_{\mathrm{L}}$ is a hydrate while in the current work water is not incorporated into the crystal lattice of Form $\mathrm{I}_{\mathrm{L}}$. The lowest $\Delta_{\text {sol }} \mathrm{H}$ for Form $\mathrm{III}_{\mathrm{L}}$ indicates this form to be least crystalline. The molar enthalpy of solution is increased with increase in the temperature (Table 3 ). The enthalpy of solution was also determined for the high melting Forms $\mathrm{I}_{\mathrm{H}}$ and $\mathrm{III}_{\mathrm{H}}$. The molar enthalpy of solution was found to be more endothermic than their corresponding low melting forms at all the temperatures which is a consequence of lattice energy being more in the higher melting stable crystal form. Moreover, the magnitude of $\Delta_{\text {sol }} \mathrm{H}$ of Forms $\mathrm{I}_{\mathrm{H}}$ and II is comparable suggesting the similar nature of their crystal lattices. The results further suggest that Form $\mathrm{III}_{\mathrm{L}}$ is a new polymorphic form.

3.5. Solubility Studies. Solubility of all the low melting and high melting forms was determined in phosphate buffer $(\mathrm{pH}$ 7.0) at $25^{\circ} \mathrm{C}$ and $37^{\circ} \mathrm{C}$ and is given in Table 3. The solubility study suggests that Form II is least soluble while Form III $_{\mathrm{L}}$ is most soluble. The solubility of Forms $\mathrm{I}_{\mathrm{H}}$ and II are almost identical indicating that they have similar free energies. These similarities agree well with thermoanalytical and XRPD data. The solubility of high melting forms $\left(\mathrm{I}_{\mathrm{H}}\right.$ and $\left.\mathrm{III}_{\mathrm{H}}\right)$ is lower than their corresponding low melting forms; however, the solubility of Form $\mathrm{III}_{\mathrm{H}}$ is found to be still higher than Forms $\mathrm{I}_{\mathrm{H}}$ and II.

3.6. Transition Temperature Determination. The transition temperature of polymorphic pairs $\mathrm{I}_{\mathrm{L}} / \mathrm{II}, \mathrm{III}_{\mathrm{L}} / \mathrm{III}_{\mathrm{H}}$, and $\mathrm{III}_{\mathrm{H}} / \mathrm{II}$ has been estimated by utilizing solubility and enthalpy of solution data. The enthalpy of transition $(\Delta \mathrm{H}(\mathrm{T}))$, free energy of transition $(\Delta G(T))$, and entropy of transition $(\Delta \mathrm{S}(\mathrm{T}))$ accompanying the transition of lower melting form to higher melting form are also determined at $25^{\circ} \mathrm{C}$ and $37^{\circ} \mathrm{C}$ using the following equations ( $\mathrm{Gu}$ and $\mathrm{Grant}$ ) and are given Table 4 one has.

$$
\Delta \mathrm{H}(\mathrm{T})=\Delta_{\text {sol }} \mathrm{H}_{\mathrm{L}}-\Delta_{\text {sol }} \mathrm{H}_{\mathrm{H}},
$$

where $\Delta_{\text {sol }} \mathrm{H}_{\mathrm{L}}$ is the enthalpy of solution of lower melting form and $\Delta_{\text {sol }} \mathrm{H}_{\mathrm{H}}$ is the enthalpy of solution of higher melting form one has

$$
\Delta \mathrm{G}(\mathrm{T})=-\mathrm{RT} \ln \frac{\mathrm{S}_{\mathrm{L}}}{\mathrm{S}_{\mathrm{H}}},
$$

where $S_{L}$ is the solubility of low melting polymorph and $S_{H}$ is the solubility of high melting polymorph.

The entropy of transition between the two forms is calculated by the following equation:

$$
\Delta \mathbf{S}(\mathbf{T})=\frac{\{\Delta \mathbf{H}(\mathbf{T})-\Delta \mathbf{G}(\mathbf{T})\}}{\mathbf{T}} .
$$

At the transition temperature, $T_{t}$,

$$
\Delta_{\text {trans }} \mathbf{G}=\mathbf{0}=\Delta_{\text {trans }} \mathbf{H}-T_{t} \times \Delta_{\text {trans }} \mathbf{S} .
$$

Hence,

$$
T_{t}=\frac{\Delta_{\text {trans }} \mathbf{H}}{\Delta_{\text {trans }} \mathbf{S}} .
$$

The negative value of $\Delta \mathrm{G}$ and $\Delta S$ for transition of $\mathrm{I}_{\mathrm{L}}$ to II indicates that higher melting forms have lower Gibb's free energy as well as lower entropy. However, the dominant factor in the free energy differences for all the polymorphic pairs at both temperatures is the difference in the enthalpy between these two phases. The transition temperature for polymorphic pairs $\mathrm{I}_{\mathrm{L}} / \mathrm{II}$ and $\mathrm{III}_{\mathrm{L}} / \mathrm{III}_{\mathrm{H}}$ was found to be higher than the melting temperature of both the forms suggesting them to be monotropically related whereas the transition temperature of polymorphic pair $\mathrm{I}_{\mathrm{H}} / \mathrm{II}$ was between $0 \mathrm{~K}$ and melting point of lower melting form indicating this pair to be enantiotropically related. 
TABLE 5: Stability of polymorphs by slurry conversion method.

\begin{tabular}{|c|c|c|c|c|c|c|c|c|}
\hline \multirow{2}{*}{ Initial polymorph } & \multicolumn{2}{|c|}{ Water } & \multicolumn{2}{|c|}{ Ethanol } & \multicolumn{2}{|c|}{ Acetonitrile } & \multicolumn{2}{|c|}{ Propanol } \\
\hline & 1 day stirring & 7 day stirring & 1 day stirring & 7 day stirring & 1 day stirring & 7 day stirring & 1 day stirring & 7 day stirring \\
\hline Form $\mathrm{I}_{\mathrm{L}}$ & $\mathrm{I}_{\mathrm{L}}$ & $\mathrm{I}_{\mathrm{L}}$ & II & II & II & II & II & II \\
\hline Form $\mathrm{III}_{\mathrm{L}}$ & $\mathrm{III}_{\mathrm{L}}$ & $\mathrm{I}_{\mathrm{L}}$ & II & II & II & II & II & II \\
\hline Form $I_{L} / \mathrm{II}$ & $\mathrm{I}_{\mathrm{L}}$ & $\mathrm{I}_{\mathrm{L}}$ & II & II & II & II & II & II \\
\hline Form $\mathrm{III}_{\mathrm{L}} / \mathrm{II}$ & $\mathrm{III}_{\mathrm{L}}$ & $\mathrm{I}_{\mathrm{L}}$ & II & II & II & II & II & II \\
\hline
\end{tabular}

3.7. Solvent Mediated Transformation and Stability of Various Forms. The previous section has shown that Form $\mathrm{III}_{\mathrm{L}}$ is most soluble which can be further used for formulation development. However, the most suitable form is the one which exhibits an appropriate balance between solubility and stability. Therefore, it is important to establish the stability of these forms. Thus the solvent mediated transformation experiments of forms $\left(\mathrm{I}_{\mathrm{L}}, \mathrm{II}\right.$, and $\left.\mathrm{III}_{\mathrm{L}}\right)$ of lamivudine were performed in water, ethanol, acetonitrile, and propanol (Table 5). Form $\mathrm{I}_{\mathrm{L}}$ is stable in water but undergoes transformation into Form II when suspended in ethanol, acetonitrile, and propanol. On the other hand, mixture of Forms $\mathrm{I}_{\mathrm{L}}$ and II slowly converts to Form II after 7 days in these solvents. Moreover, water has no effect on Form $\mathrm{III}_{\mathrm{L}}$ up to $24 \mathrm{~h}$ but it undergoes a transformation to Form $\mathrm{I}_{\mathrm{L}}$ after 7 days. However, it transforms to stable Form II in ethanol, acetonitrile, and propanol. The analysis of forms recovered after suspending solvents revealed that Form $\mathrm{I}_{\mathrm{L}}$ is preferred over Form II in water whereas in ethanol, acetonitrile, and propanol Form II is the preferred form.

\section{Conclusion}

The DSC and SEM results suggest that Forms I and III in the present study are sensitive to thermal stress and the heat mediated transformation of these forms leads to generation of stable Form II and a new polymorphic form, respectively. The interpretation of the DSC data is facilitated by visual observations in thermal microscopy. Monotropic relationship has been identified in the polymorphic pairs $I_{L} / I I$ and $\mathrm{III}_{\mathrm{L}} / \mathrm{III}_{\mathrm{H}}$ while Form $\mathrm{III}_{\mathrm{H}}$ is shown to be enantiotropic modification of Form II. On the basis of comparison of differences between the enthalpies of solution and XRPD data, Form $\mathrm{III}_{\mathrm{L}}$ is found to be least crystalline and most soluble. However, the metastable Form $\mathrm{I}_{\mathrm{L}}$, which shows better solubility than Form II, though transforms to Form II in solvents but is stable in aqueous suspension and can be categorized as suitable candidate for solid dosage.

\section{Acknowledgments}

The financial support provided by Department of Science and Technology (DST) and Council for Scientific Research (CSIR), India, is gratefully acknowledged.

\section{References}

[1] R. A. E. Castro, T. M. R. Maria, A. O. L. Évora et al., "A new insight into pyrazinamide polymorphic forms and their thermodynamic relationships," Crystal Growth and Design, vol. 10, no. 1, pp. 274-282, 2010.

[2] G. Madras and B. J. McCoy, "Growth and ripening kinetics of crystalline polymorphs," Crystal Growth and Design, vol. 3, no. 6, pp. 981-990, 2003.

[3] M. Grčman, F. Vrečer, and A. Meden, "Some physico-chemical properties of doxazosin mesylate polymorphic forms and its amorphous state," Journal of Thermal Analysis and Calorimetry, vol. 68, no. 2, pp. 373-387, 2002.

[4] K. Park, J. M. B. Evans, and A. S. Myerson, "Determination of solubility of polymorphs using differential scanning calorimetry," Crystal Growth and Design, vol. 3, no. 6, pp. 991-995, 2003.

[5] K. Kawakami, "Reversibility of enantiotropically related polymorphic transformations from a practical viewpoint: thermal analysis of kinetically reversible/irreversible polymorphic transformations," Journal of Pharmaceutical Sciences, vol. 96, no. 5, pp. 982-989, 2007.

[6] S. Jiang, P. J. Jansens, and J. H. ter Horst, "Mechanism and kinetics of the polymorphic transformation of $o$-aminobenzoic acid," Crystal Growth and Design, vol. 10, no. 5, pp. 2123$2128,2010$.

[7] C. Gu -H, V. Young Jr., and D. J. W. Grant, "Polymorph screening: influence of solvents on the rate of solvent-mediated polymorphic transformation," Journal of Pharmaceutical Sciences, vol. 90, no. 11, pp. 1878-1888, 2001.

[8] R. Panchagnula, P. Sundaramurthy, O. Pillai, S. Agrawal, and Y. A. Raj, "Solid-state characterization of mefenamic acid," Journal of Pharmaceutical Sciences, vol. 93, no. 4, pp. 1019-1029, 2004.

[9] O. 'Neil MJ, P. E. Heckelman, C. B. Koch, and K. J. Roman, The Merck Index, An Encyclopedia of Chemicals, Drugs and Biologicals, Merck \& Company, Inc., Whitehouse Station, NJ, USA, 14th edition, 2006.

[10] J. G. Hardman, L. E. Limbird, and A. G. Gilman, The Pharmacological Basis of Therapeutics, McGraw Hill Medical Publishing Division, New York, NY, USA, 10th edition, 2001.

[11] M. J. Jozwiakowski, N. A. T. Nguyen, J. M. Sisco, and C. W. Spancake, "Solubility behavior of lamivudine crystal forms in recrystallization solvents," Journal of Pharmaceutical Sciences, vol. 85, no. 2, pp. 193-199, 1996.

[12] R. K. Harris, R. R. Yeung, R. B. Lamont, R. W. Lancaster, S. M. Lynn, and S. E. Staniforth, "Polymorphism' in a novel antiviral agent: lamivudine," Journal of the Chemical Society. Perkin Transactions 2, no. 12, pp. 2653-2659, 1997.

[13] G. P. Singh, S. Dhananjai, M. B. Saini, and P. Upadhyay, "A novel crystalline form of lamivudine," WO, 2007/119248 A1, 2007.

[14] C. H. Gu and D. J. W. Grant, "Estimating the relative stability of polymorphs and hydrates from heats of solution and solubility data," Journal of Pharmaceutical Sciences, vol. 90, no. 9, pp. 1277-1287, 2001. 

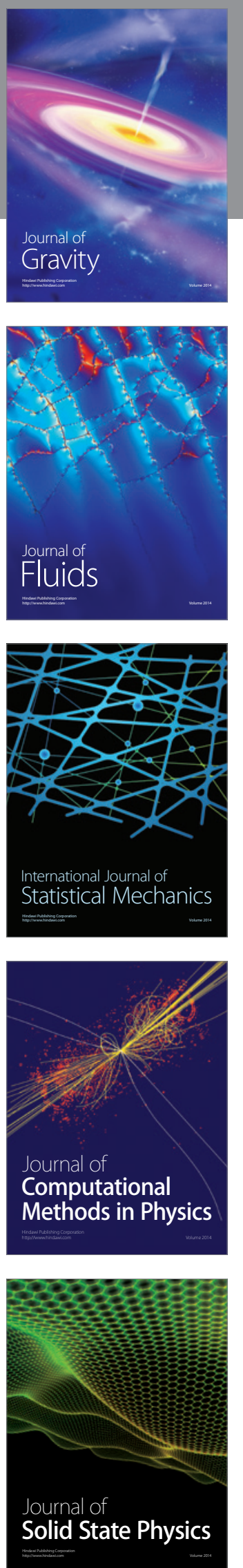
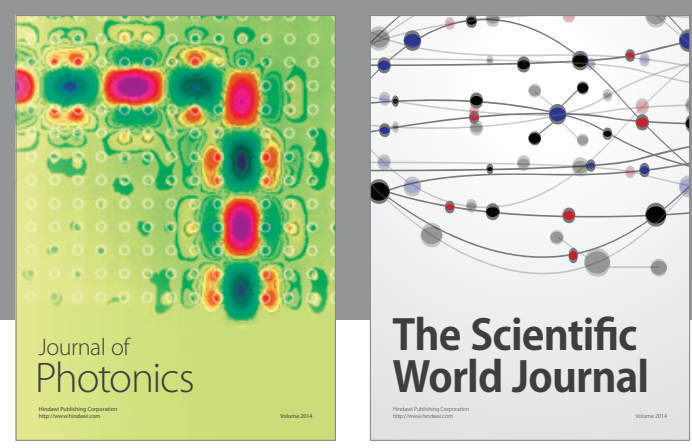

The Scientific World Journal

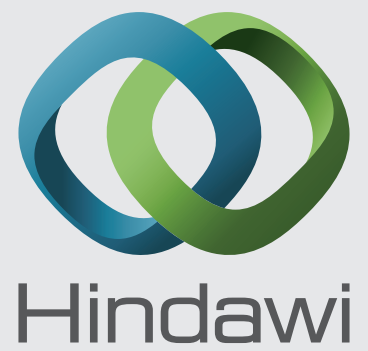

Submit your manuscripts at http://www.hindawi.com
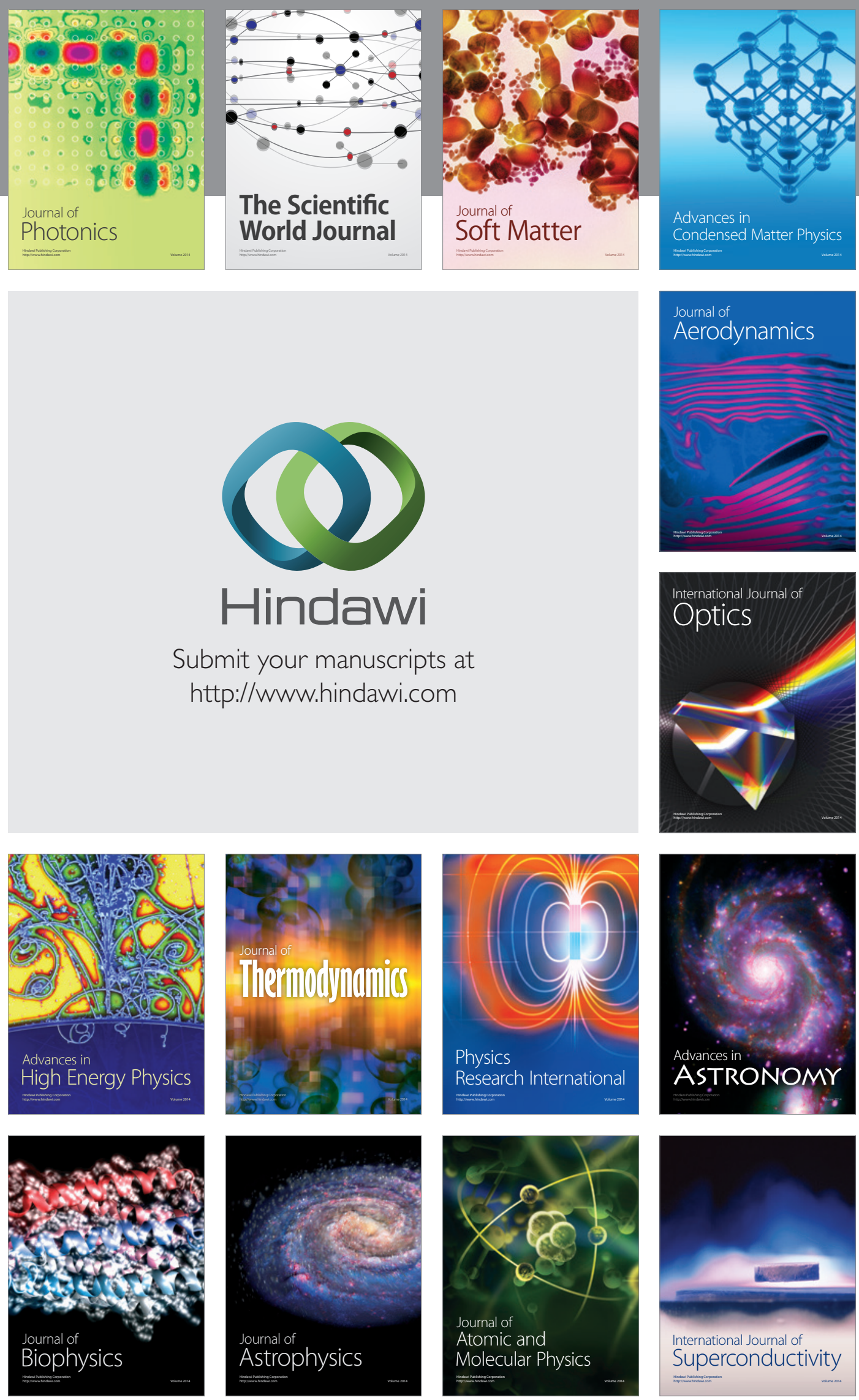
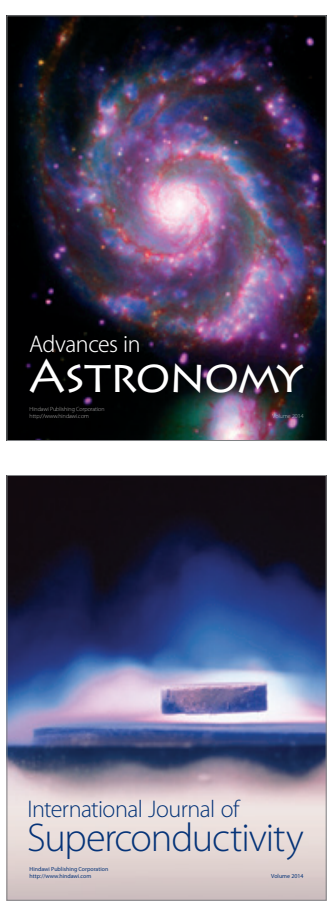